\title{
Correlation between selective laser melting parameters, pore defects and tensile properties of $99.9 \%$ silver
}

\author{
John Robinson ${ }^{1,2 *}$, Mark Stanford ${ }^{2}$, Arun Arjunan $^{1}$ \\ ${ }^{1}$ School of Engineering, University of Wolverhampton, Telford Innovation Campus, Telford TF2 9NT, UK \\ ${ }^{2} 6$ DME Ltd., Stirchley Road, Telford TF3 1EB, UK
}

\begin{abstract}
In this study the relationship between Selective Laser Melting (SLM) process parameters, associated pore defects and resulting tensile properties of additively manufactured (AM) pure (99.9\%) silver structures are investigated using X-ray Computed Tomography (XCT) and 3D visualisation analysis. Yield strength, Young's Modulus, failure strain and ultimate tensile strength of AM pure silver are reported. Furthermore, fracture surfaces of the samples are analysed using optical microscopy and Scanning Electron Microscopy (SEM) to investigate fracture surface porosity content and surface roughness is analysed using digital microscopy. Pore defect distribution, morphology and resultant pore surface area are reported, and average pore size calculated in relation to SLM process parameters variations. It was found that sample yield and ultimate tensile strengths of pure silver have a direct correlation with energy density at the powder bed related to SLM process parameters selected. However, Youngs Modulus values were found to be dependent on the average porosity pore size rather than sample density or number of pores. SLM pure silver bulk density was evaluated using XCT comparative analysis while varying SLM parameters and the resultant pore defect morphology and distribution discussed. The results reported in this work serve as a basis for further material development and mechanical property predictions utilising XCT analysis for pure silver and other nonstandard SLM materials.
\end{abstract}

Keywords: Additive Manufacturing; Selective Laser Melting; Parameters; Computed Tomography; Pure Silver; Tensile; Density; Porosity; Youngs modulus; Yield strength

\footnotetext{
* Corresponding author: SC120, School of Engineering, University of Wolverhampton Telford Innovation Campus, Telford, TF2 9NT, UK Tel.: +44 1902323958

E-mail address: john@6dme.com (John Robinson)
} 


\section{Introduction}

Additive Manufacturing (AM) is a manufacturing technique which joins materials rather than forming or subtracting materials as with more traditional technologies [1]. There are many AM processes (powder bed, direct deposition and extrusion) and materials (polymer, ceramic and metal) $[2,3]$ where material is usually added layer by layer to create $3 \mathrm{D}$ components defined by digital data [1]. Selective Laser Melting (SLM) is an AM technique which typically uses highpowered laser energy for SLM metal alloys and metal matrix composite materials layer upon layer $[4-6]$.

SLM allows the fabrication of near fully dense complex metallic structures that are difficult or impossible to manufacture through traditional manufacturing technologies $[7,8]$. Therefore SLM is experiencing interest from high value sectors such as aerospace, automotive and biomedical [9-12]. However, the SLM process is complex and involves material alloying, chemical reactions, material absorptivity, laser diffusion and scattering, heat transfer and material phase transformation [13]. As such the mechanical properties produced by the SLM process are a result of parameters related to material feedstock, build process and post processing techniques [14] of which there is in excess of 130 variables [14].

The wide range of feedstock material and process variables as well as manufacturing variations have been shown to effect several material characteristics including surface roughness [15] microstructure [16] and density. All of which have the potential to lead to porosity defects within AM components [14,17-19]. Furthermore, the effects of porosity type, and distribution, for AM materials are not fully understood. This is predominantly due to lack of understanding between the associated feedstock and process variables [20-22], particularly for novel nonstandard materials such as silver [23]. Understanding the relationship between feedstock and process parameters on fabricated component defects is critical to analyse the mechanical properties and potential failure modes of AM materials and components [24,25]. Accordingly, this work reports the effects of SLM process parameters on component density, porosity defects and mechanical properties of AM pure silver.

Silver is highly reflective with high thermal and electrical conductance $[26,27]$ whilst having antimicrobial properties [28]. Silver and silver alloys are being researched for applications including electronic, biomedical, renewable energy and thermal management [26-29]. Previous processing of silver and silver alloys utilising SLM Additive Manufacturing (AM) has seen limited attention with varying success [23,30]. However, the powder feedstock composition, morphology, distribution and SLM processing parameters have been shown to have a significant effect on AM processability $[23,29,30]$ and resultant thermomechanical properties [29,31]. Recent studies have investigated the fabrication of 3D cube structures utilising SLM and atomised pure silver powder concluding the processing of pure silver utilising SLM is feasible [30]. However, significant 
porosity defects were highlighted through Optical and Scanning Electron Microscopy (SEM) analysis.

Manufacturing defects can have a negative effect on AM fabricated components $[18,32,33]$ and while traditional metallographic preparation and analysis techniques such as mechanical grinding, polishing and chemical etching can be combined with SEM and optical microscopy analysis to offer an insight into component microstructure [34] and density these techniques offer limited information in regards of AM pore defect morphology, size and distribution. Recently Xray Computed Tomography (XCT) has been used for these investigations as it is a none destructive analysis technique for 3D visualisation of $\mathrm{AM}$ component density and defect distribution $[35,36]$. The work presented in this study reports the relationship between SLM process parameters and component density and tensile properties for AM pure silver structures which to the authors knowledge are yet to be reported in literature. Manufacturing porosity defect type and distribution are described through XCT 3D visualisation and fracture surfaces are analysed utilising SEM and optical microscopy techniques. Accordingly, the relationship between AM process parameters on resultant density and Youngs Modulus, ultimate tensile strength, yield strength and strain failure for various SLM process parameters of fabricated pure silver structures are reported.

\section{Material and methods}

The investigations presented in this paper were carried out on an EOS M290 industrial grade AM system using atomised pure (99.9\%) silver powder (Fig 1) supplied by Legor Group S.p.A. Powder morphology and Particle Size Distribution (PSD) have been shown to affect the flowability and packing density of AM powders [21] and therefore can dictate the thermomechanical behaviour of powders during the AM process [21].

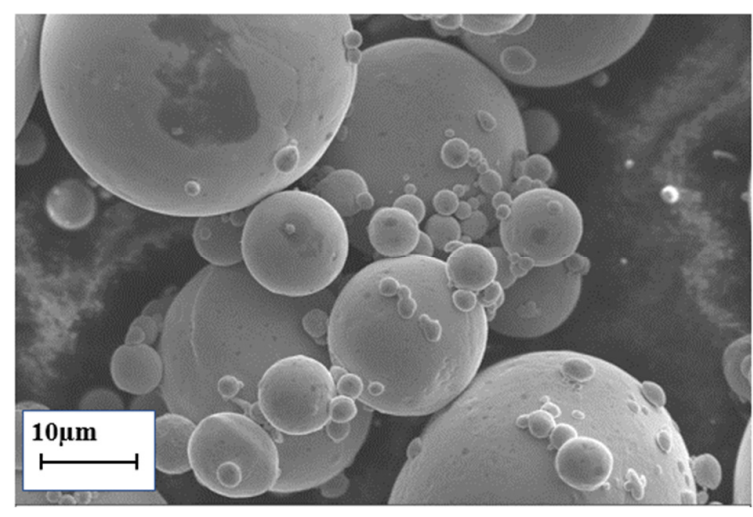

(a)

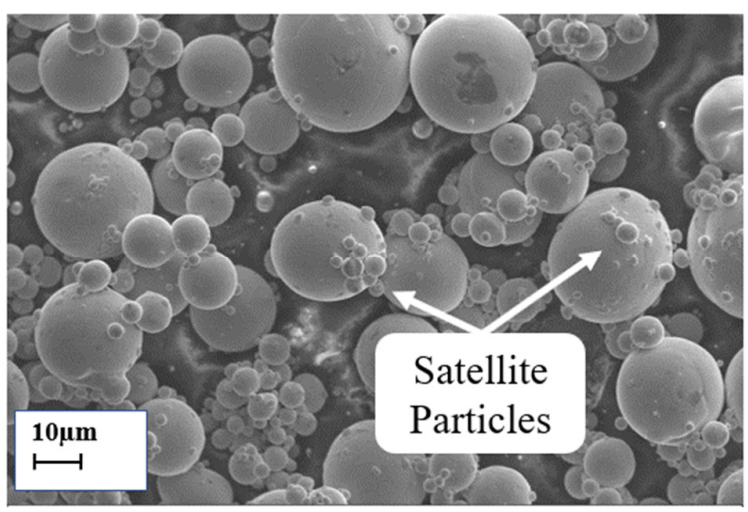

(b)

Fig 1. Scanning Electron Microscopy (SEM) image for 99.9\% pure silver powder showing (a) powder morphology and (b) satellite particles distribution. 
Previous studies [30] investigated the powder morphology and particle distribution characteristics of pure silver powder using dynamic image analysis and concluded that with a D10 of $18.8 \mu \mathrm{m}$, D50 of $27.6 \mu \mathrm{m}$ and D90 of $38.6 \mu \mathrm{m}$ the pure silver powder had a suitable morphology and particle distribution for SLM processing [30]. Fig 1 shows Scanning Electron Microscopy (SEM) images of the pure silver powder utilised for this study. Fig 1a highlights the spherical morphology of the powder particles which is desired for the SLM process to enhance both the packing density and flowability of the powder [21]. However, the presence of numerous satellite particles seen in Fig 1b could negatively affect the packing density and flowability of the powder which could in turn effect powder delivery to the exposure area.

The SLM process utilised in this study features a $400 \mathrm{~W}$ laser with $100 \mu \mathrm{m}$ spot size and all builds were completed in an argon atmosphere with oxygen content in the process chamber below $0.1 \%$. The process was carried out on substrates heated to $35^{\circ} \mathrm{C}$ and standard rotation scanning strategy and $30 \mu \mathrm{m}$ layer thicknesses were kept constant for all builds. Following on from previous studies tensile samples (Fig 2) were fabricated using $400 \mathrm{~mm} / \mathrm{s}$ and $800 \mathrm{~mm} / \mathrm{s}$ scan speeds at hatch distances of $0.15 \mathrm{~mm}, 0.16 \mathrm{~mm}, 0.18 \mathrm{~mm}$ and $0.20 \mathrm{~mm}$ to ascertain differences in energy density input at the powder bed. Small tensile samples were fabricated to reduce material usage and cost related to pure silver.

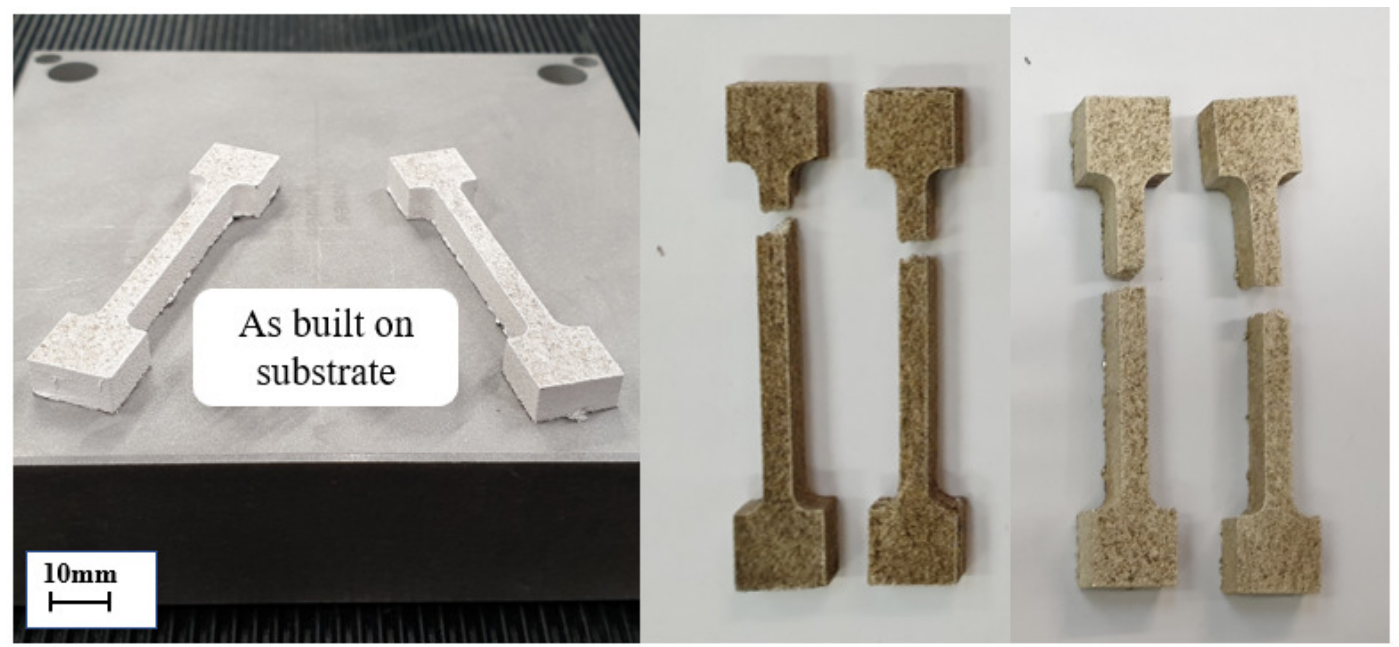

(a)

(b)

Fig 2. Pure silver tensile test samples (a) as built on build substrate and (b) following EDM and tensile testing.

Fig 2a shows tensile test samples fabricated using SLM and pure silver powder as built on build substrate. Following fabrication all samples were removed from the build platform using none contact Electrical Discharge Machining (EDM) techniques. Quasi-static mechanical tests were carried out using a Zwick Roell 1474 universal testing machine at a rate of $0.06 \mathrm{~mm} / \mathrm{s}$. A Bruker Skyscan 2211 X-ray nanotomograph was used to analyse sample pore defects distribution and 
morphology. Scan parameters utilised were $360^{\circ}$ scan with $0.05^{\circ}$ step increments and two frames per increment. Fracture surface was then analysed using optical microscopy and SEM techniques.

\section{Results and discussion}

\subsection{Tensile performance}

Silver with high reflectivity, thermal and electrical conductance [26,27] and antimicrobial properties [28] is of interest for electrical, biomedical, renewable energy and thermal management applications [26-29]. However, little is known regarding pure silver SLM processability and resultant mechanical properties. Accordingly, Fig 3 presents the stress-strain $(\sigma-\varepsilon)$ curve for AM pure silver tensile samples with varying scan speed and hatch distances. The performance parameters such as the Yield strength $\left(\sigma_{y}\right)$, Youngs Modulus $(\mathrm{E})$, failure strain $\left(\varepsilon_{f}\right)$ and ultimate tensile strength (UTS) values and corresponding hatch distances values can be seen in Fig 4 .

$$
\begin{array}{rrrr}
-0.15 \mathrm{~mm} & \cdots \cdot 0.15 \mathrm{~mm}(2) & -0.16 \mathrm{~mm} & -0.0 .16 \mathrm{~mm}(2) \\
-0.18 \mathrm{~mm} & -0.18 \mathrm{~mm}(2) & -0.20 \mathrm{~mm} & -0.20 \mathrm{~mm}(2)
\end{array}
$$

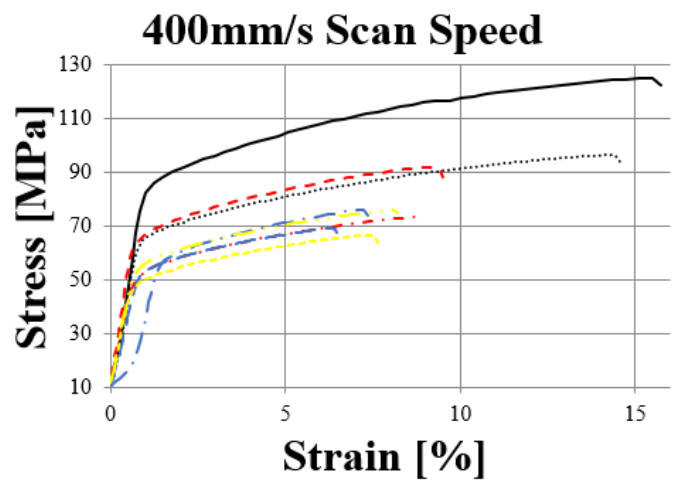

(a)

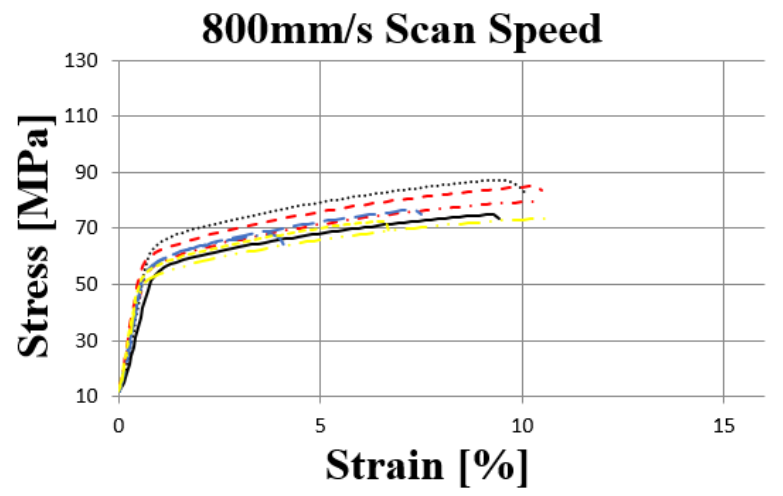

(b)

Fig 3. Stress-strain curve for AM pure silver at $0.15,0.16,0.18 \mathrm{~mm}$ and $0.20 \mathrm{~mm}$ hatch distances at (a) $400 \mathrm{~mm} / \mathrm{s}$ scan speed and (b) $800 \mathrm{~mm} / \mathrm{s}$ scan speed.

Previous studies [30] on SLM pure silver have shown successful single-track fabrication widths between $0.15 \mathrm{~mm}$ and $0.18 \mathrm{~mm}$ where optimum scan speeds were identified to be between $550 \mathrm{~mm} / \mathrm{s}$ and $800 \mathrm{~mm} / \mathrm{s}$ for continuous stable track formation [30]. However, 3D structures fabricated using these scan speed parameters were also shown to result in significant porosity creation bringing into question the correlation between single track formation and dense 3D structures. Furthermore, it has been shown that SLM process parameters effect porosity and mechanical properties [37-39] with increased energy resulting in reduced porosity. Therefore, to further investigate the effects of SLM process parameters on porosity content and mechanical properties of pure silver the parameters selected for this study have lower scan speeds and larger hatch distance than previous studies to increase and reduce the energy density respectively. Therefore, hatch distances between $0.15 \mathrm{~mm}$ and $0.20 \mathrm{~mm}$ and scan speeds of $400 \mathrm{~mm} / \mathrm{s}$ and 
$800 \mathrm{~mm} / \mathrm{s}$ were selected for this study. $400 \mathrm{~mm} / \mathrm{s}$ scan speeds saw yield strength decrease as hatch distance increased from $67.02 \mathrm{MPa}$ to $41.86 \mathrm{MPa}$; a difference of $37 \%$ (25.16 MPa) between $0.15 \mathrm{~mm}$ and $0.20 \mathrm{~mm}$ hatch distances. $800 \mathrm{~mm} / \mathrm{s}$ scan speeds also saw yield strength decrease as hatch distance increased however the rate of decrease was smaller at $14 \%$ from 52.9 MPa to 45.53 MPa; an absolute difference of 7.37 MPa. Youngs modulus for both scan speeds (400 and $800 \mathrm{~mm} / \mathrm{s}$ ) varied between $10.11 \mathrm{GPa}$ and $16.39 \mathrm{GPa}$; a difference of $62 \%$ with no obvious correlation with SLM parameters used. However, as with increase in hatch distance, a higher scan speed of $800 \mathrm{~mm} / \mathrm{s}$ resulted in stiffer parts as represented by $5 \mathrm{~b}$. Nevertheless, as can be seen a similar bimodal trend can be observed as the hatch distance increases although the absolute values of the Young's modulus differ.

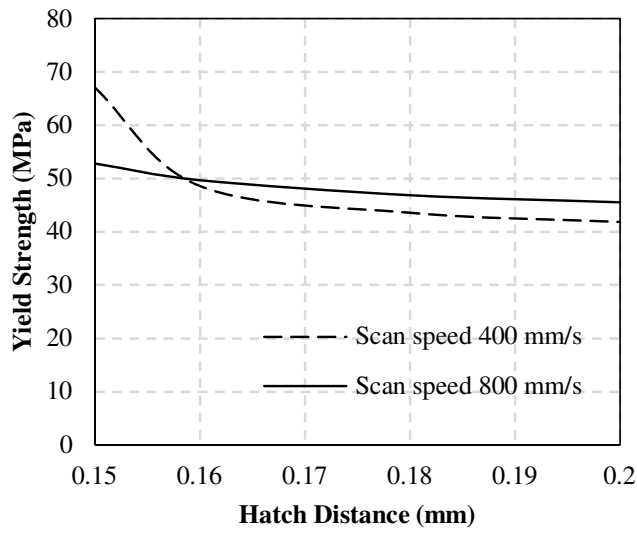

(a)

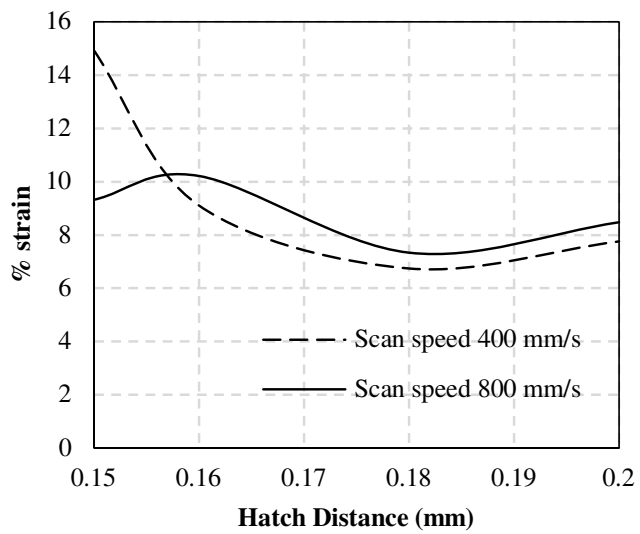

(c)

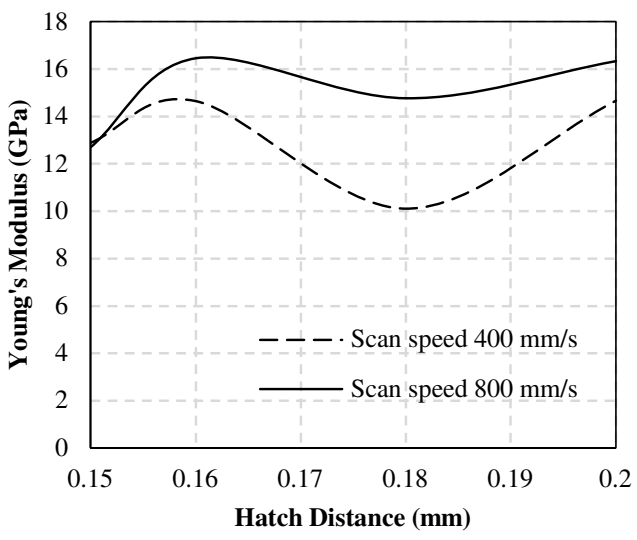

(b)

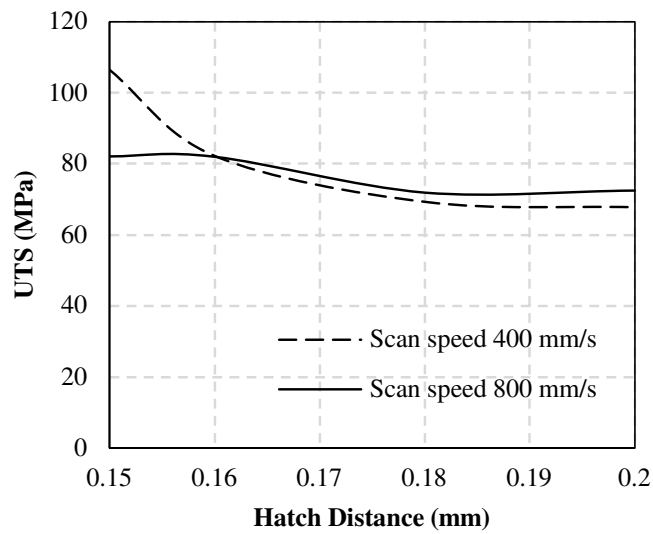

(d)

Fig. 4. Influence of hatch distance and scan speed on the mechanical performance of SLM pure silver where (a) shows the effect on Yield strength, (b) Young's modulus, (c) failure strain and (d) Ultimate tensile strength

Energy density at the powder bed effected by scan speed and hatch distance variations had direct effect on yield strength (Fig. 4a) but not Youngs modulus (Fig. 4b) values of the samples. 
Failure strain results varied between $14.91 \%$ and $6.74 \%$ with maximum deformation also seen with $400 \mathrm{~mm} / \mathrm{s}$ scan speed and $0.15 \mathrm{~mm}$ hatch distance parameters which also had the highest yield strength. Overall yield and ultimate strength directly related to energy density input at the powder bed with the highest and lowest performing yield and ultimate tensile strengths being the smallest and largest hatch distance values respectively. Overall smaller hatch distances were shown to give higher yield strength and ultimate tensile strength. To further evaluate tensile performance X-ray Computed Tomography (XCT) was used to analyse pure silver sample density and porosity defect distribution, morphology and content. The highest and lowest yield strength samples for $400 \mathrm{~mm} / \mathrm{s}$ scan speeds were $0.15 \mathrm{~mm}$ and $0.20 \mathrm{~mm}$ hatch distances. Therefore, these samples were selected and analysed in comparison to $800 \mathrm{~mm} / \mathrm{s}$ scan speed and $0.15 \mathrm{~mm}$ hatch distance sample which had the highest yield strength yet lowest Youngs modulus of the $800 \mathrm{~mm} / \mathrm{s}$ scan speed samples. Furthermore, the fracture surface of $400 \mathrm{~mm} / \mathrm{s}$ scan speed at $0.16 \mathrm{~mm}$ and $0.15 \mathrm{~mm}$ hatch distances were analysed with SEM and optical microscopy.

\subsection{X-ray Computed Tomography}

While optical and scanning electron microscopy analysis supply an indication of fabricated component density and surface defects, they offer limited information on morphology and distribution of internal defects of the fabricated structures. While porosity size can be evaluated using traditional techniques, porosity morphology and volumetric distribution throughout the sample is not visible. In this regard, XCT is a none destructive analysis technique that has recently seen increasing investigation towards becoming an established tool for AM defect analysis $[32,35]$.

Incorrect powder feedstock properties such as PSD and flowability can lead to nonuniform powder layer delivery and porosity defects. However, porosity defects can also occur due to laser and material interaction and process and scanning strategy parameters [19]. Lack of fusion, blowhole and keyhole porosities have been shown to be created while SLM processing of pure silver, however, the pore defect size and distribution information is limited with optical microscopy and SEM 2D analysis techniques. Accordingly, XCT analysis was conducted to ascertain 3D porosity morphology and distribution and the effects related to selected SLM process parameters, pure silver tensile properties and material failure.

XCT analysis was conducted utilising a Bruker Skyscan 2211 X-ray nanotomograph. Although $\mathrm{XCT}$ analysis is a valuable tool for nondestructive analysis, the results to a large extent is dependent on the scanning and threshold parameters set during the process. XCT analysis is a good technique for comparative analysis rather than absolute analysis as the process can be easily adjusted and the threshold between good separation between density and porosity is subjective and is set using the histogram by the user. Furthermore, XCT analysis will generally

underestimate total porosity due to the limitation of resolution. The maximum porosity that

Page 7 of 18 
will be visible with confidence will be a minimum of 5 pixels. Therefore, the size of porosity that can be detected is dependent on the pixel size set during XCT scanning set up. Although camera resolution and pixel size can be adjusted as part of XCT set up the minimum pixel size is limited dependent on the size of the sample being processed. Any porosity below the set range may be seen but will appear less bright in the scan. For this reason, all samples were scanned with the same XCT scanning, threshold and reconstruction parameters to ensure any notable changes in porosity was due to the AM manufacturing parameters and not the XCT scanning operation and analysis. As samples were compared in like for like structures at the same pixel resolution, we can be confident that the differences in density and porosity defects was due to AM feedstock material and process parameters used for manufacturing.

\subsection{Porosity Defect 3D Visualisation}

The bulk density, closed pore porosity content and surface area for all the samples evaluated using XCT analysis are presented in Table 1 while the corresponding X-ray absorption 3D visualisations for $800 \mathrm{~mm} / \mathrm{s} 0.15 \mathrm{~mm}$ and $400 \mathrm{~mm} / \mathrm{s}$ at $0.15 \mathrm{~mm}$ and $0.20 \mathrm{~mm}$ samples are shown in Fig 5.

\begin{tabular}{cccccc}
\hline $\begin{array}{c}\text { Scan speed } \\
(\mathbf{m m} / \mathbf{s})\end{array}$ & $\begin{array}{c}\text { Hatch } \\
\text { distance } \\
(\mathbf{m m})\end{array}$ & $\begin{array}{c}\text { Bulk } \\
\text { density } \\
(\mathbf{\%})\end{array}$ & $\begin{array}{c}\text { Number } \\
\text { of closed } \\
\text { pores }\end{array}$ & $\begin{array}{c}\text { Surface of } \\
\text { closed pores } \\
\left(\mathbf{m m}^{2}\right)\end{array}$ & $\begin{array}{c}\text { Average pore } \\
\text { size }\left(\mathbf{m m}^{2}\right)\end{array}$ \\
\hline 400 & 0.15 & 99.8 & 166 & 2.196 & 0.0132 \\
400 & 0.16 & 86.5 & 1374 & 11.242 & 0.0082 \\
400 & 0.18 & 96.0 & 2452 & 38.321 & 0.0156 \\
400 & 0.20 & 94.0 & 3421 & 26.900 & 0.0079 \\
800 & 0.15 & 99.5 & 532 & 7.419 & 0.0139 \\
800 & 0.16 & 98.5 & 1580 & 13.597 & 0.0086 \\
800 & 0.18 & 99.8 & 323 & 1.917 & 0.0059 \\
800 & 0.20 & 94.6 & 2270 & 15.300 & 0.0067 \\
\hline
\end{tabular}

Table 1. XCT pore defect properties for SLM pure silver samples with 400 and $800 \mathrm{~mm} / \mathrm{s}$ scan speeds and 0.15 , $0.16,0.18$ and $0.20 \mathrm{~mm}$ hatch distances parameters.

X-ray absorption rates varied for all samples. 3D visualisations were created (Fig 5) where relatively dense material (high X-ray absorption) was represented by 1 (blue) while 0 (black) represented relatively low X-Ray absorption and therefore potential porosity voids. Overall lower hatch distance values $(0.15 \mathrm{~mm})$ corresponded with higher material density (Fig 5a and 5b). To analyse pore defect morphology and distribution throughout the samples the internal closed pore porosity voids were isolated and can be seen highlighted in red in Fig 6 . 


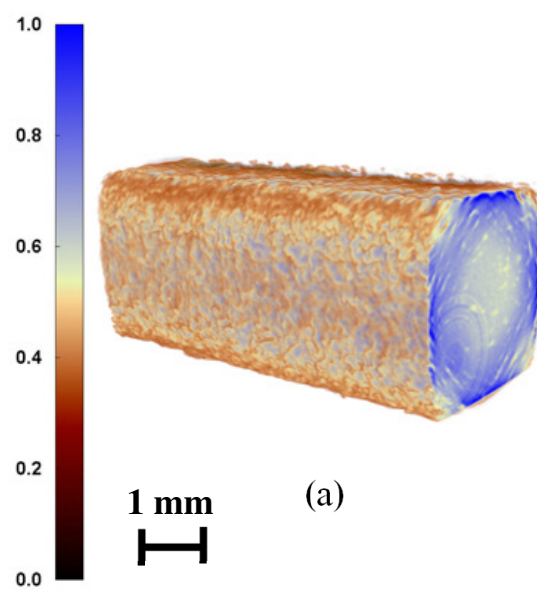

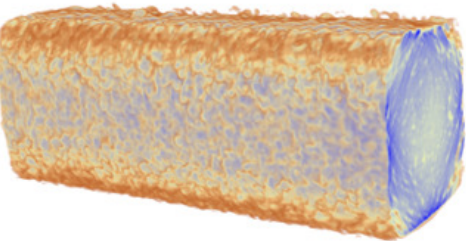

(b)

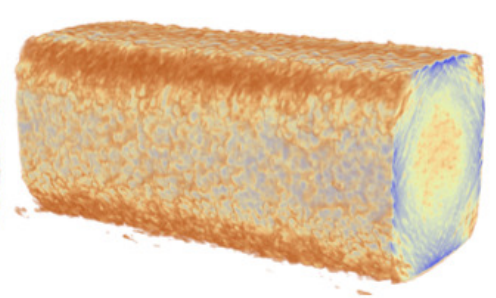

(c)

Fig 5. XCT X-ray absorption visualisation for (a) $0.15 \mathrm{~mm}$ hatch distance $400 \mathrm{~mm} / \mathrm{s}$ scan speed (b) $0.15 \mathrm{~mm}$ hatch distance $800 \mathrm{~mm} / \mathrm{s}$ scan speed. and (c) $0.20 \mathrm{~mm}$ hatch distance and $400 \mathrm{~mm} / \mathrm{s}$ scan speed.

Energy density at the powder bed resulting from varying SLM scan speed parameters can be seen to affect not only porosity distribution throughout the sample but also porosity morphology and therefore the number and surface area of the pore defects. While bulk density was shown to be comparable for both $0.15 \mathrm{~mm}$ hatch distance and $400 \mathrm{~mm} / \mathrm{s}$ and $800 \mathrm{~mm} / \mathrm{s}$ being $99.8 \%$ and 99.5\% respectively the number of pores and therefore the surface area of those pores varied significantly.

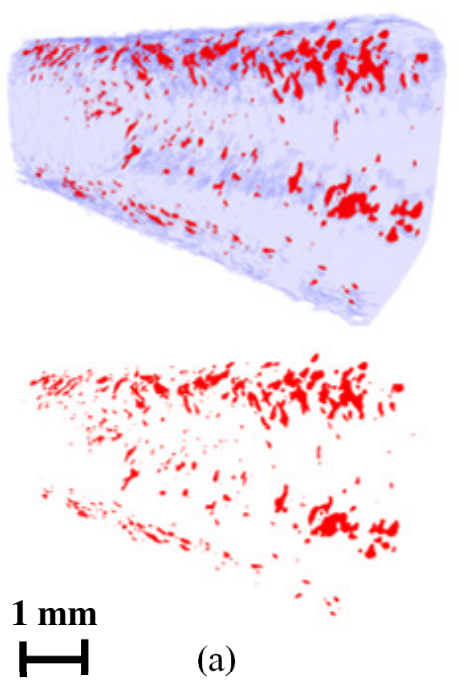

1 (a)
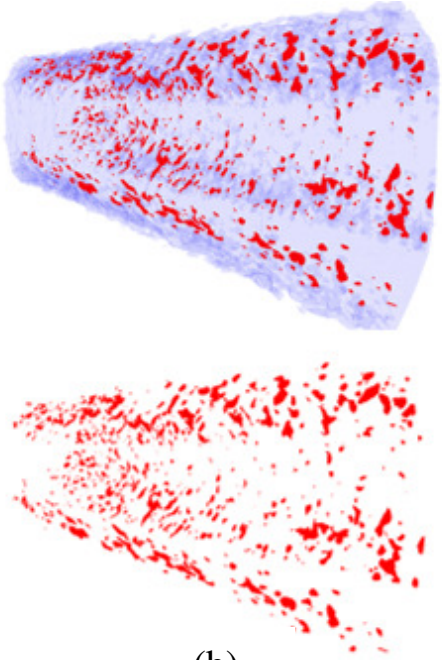

(b)
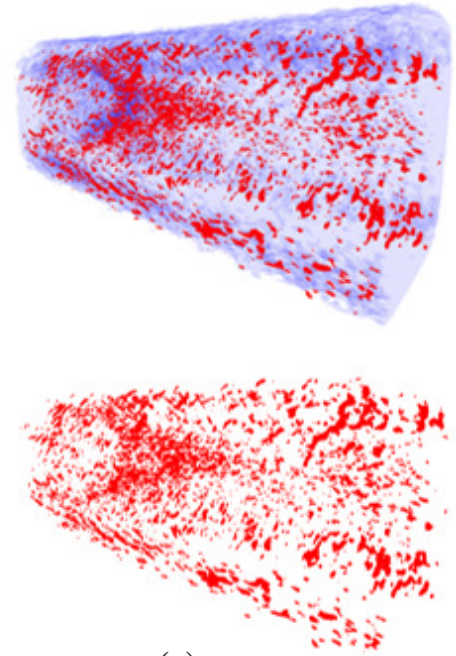

(c)

Fig 6. XCT 3D visualisation of porosity content and distribution for (a) $0.15 \mathrm{~mm}$ hatch distance $400 \mathrm{~mm} / \mathrm{s}$ scan speed (b) $0.15 \mathrm{~mm}$ hatch distance $800 \mathrm{~mm} / \mathrm{s}$ scan speed. and (c) $0.20 \mathrm{~mm}$ hatch distance and $400 \mathrm{~mm} / \mathrm{s}$ scan speed.

The scan speed of $400 \mathrm{~mm} / \mathrm{s}$ resulted in the lowest number of closed pore defects of 166 in comparison to 532 for $800 \mathrm{~mm} / \mathrm{s}$ under identical hatch distance. 400mm/s scan speed (Fig 6a) can be seen to produce larger irregular shaped porosity defects confined to certain regions of the 
sample while $800 \mathrm{~mm} / \mathrm{s}$ scan speed (Fig 6b) also created smaller porosity defects distributed at a larger proportion throughout the sample. Reducing energy density at the powder bed further by maintaining a $400 \mathrm{~mm} / \mathrm{s}$ scan speed while increasing the hatch distance to $0.20 \mathrm{~mm}$ increased the number of pores to 2270 while reducing sample density to $94.6 \%$ as shown in Fig 6c.

Porosity defects produced during the SLM process have seen significant investigation $[18,19,40]$ and are generally characterised to be either lack of fusion, keyhole and blowhole defects [19]. While keyhole and blowhole pore defects are spherical in shape and are caused by trapped gas, lack of fusion porosity appear as larger irregular shaped pores [19]. These can be caused by insufficient powder delivery and/or insufficient energy at the powder bed. Furthermore, powder morphology as well as unoptimised parameters for specific sample areas, such as incorrect bulk and contour parameters could result in pore defect generation.

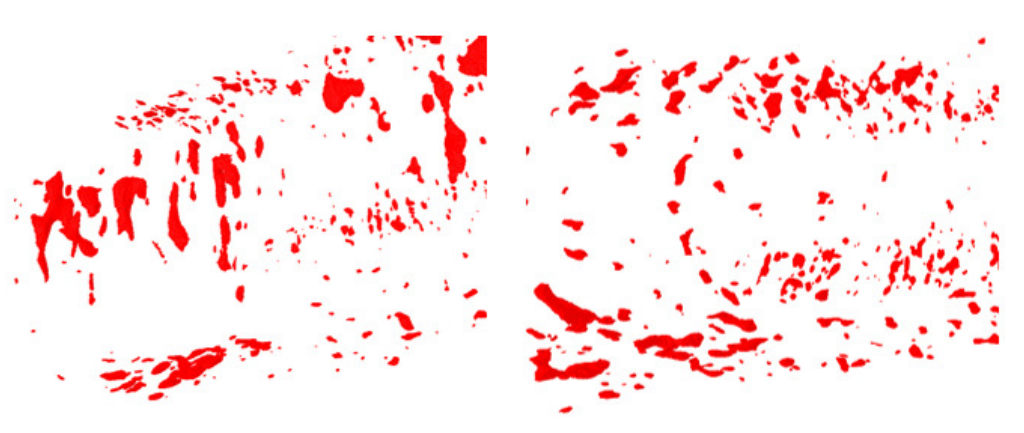

$300 \mu \mathrm{m}$ (a)

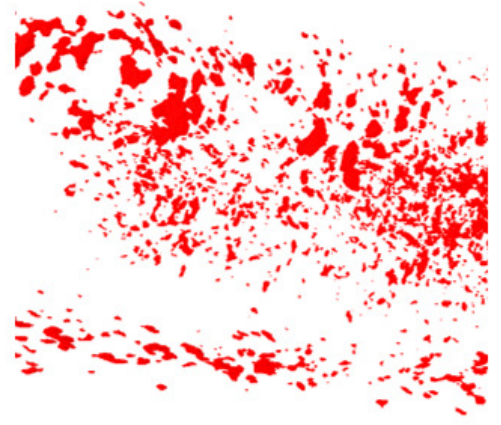

(c)

Fig 7. XCT 3D visualisation of porosity morphology for (a) $0.15 \mathrm{~mm}$ hatch distance $400 \mathrm{~mm} / \mathrm{s}$ scan speed (b) $0.15 \mathrm{~mm}$ hatch distance $800 \mathrm{~mm} / \mathrm{s}$ scan speed. and (c) $0.20 \mathrm{~mm}$ hatch distance and $400 \mathrm{~mm} / \mathrm{s}$ scan speed.

Fig 7 shows porosity morphology for $0.15 \mathrm{~mm}$ hatch distance at $400 \mathrm{~mm} / \mathrm{s}$ and $800 \mathrm{~mm} / \mathrm{s}$ and $0.20 \mathrm{~mm}$ hatch distance and $400 \mathrm{~mm} / \mathrm{s}$ scan speed. Fig 7a highlights the larger irregular shaped pore morphology produced by $400 \mathrm{~mm} / \mathrm{s}$ scan speed and $0.15 \mathrm{~mm}$ hatch distance suggesting lack of fusion porosity defects. Fig 7b highlights an increase in finer porosity distribution with an increase in scan speed while Fig 7c highlights a significant increase in pore defects due to larger hatch distance of $0.20 \mathrm{~mm}$. The porosity morphology and distribution in Fig 7b and Fig 7c suggests that reducing energy density at the powder bed with either increased scan speed or larger hatch distance increases keyhole and blowhole porosity defects throughout the samples.

Fig 7a suggests that although laser energy at the powder bed is higher due to the relatively slower scan speed the porosity produced is lack of fusion porosity. Therefore, the samples produced have suffered from either insufficient powder delivery due to powder feedstock and/or insufficient energy at the powder bed due to unoptimised parameters. Further analysing pore distribution XCT 3D visualisations for samples in $\mathrm{Z}$ and $\mathrm{X}$ views were created and can be seen 
in Fig 8. While it can still be seen that pore content increases with increased hatch distance it can also be seen that the lack of fusion porosity for both $400 \mathrm{~mm} / \mathrm{s}$ scan speed $0.15 \mathrm{~mm}$ hatch distance (Fig 8a) and $800 \mathrm{~mm} / \mathrm{s}$ scan speed $0.15 \mathrm{~mm}$ hatch distance (Fig $8 \mathrm{~b}$ ) is more prevalent in the outer contour areas of the samples.
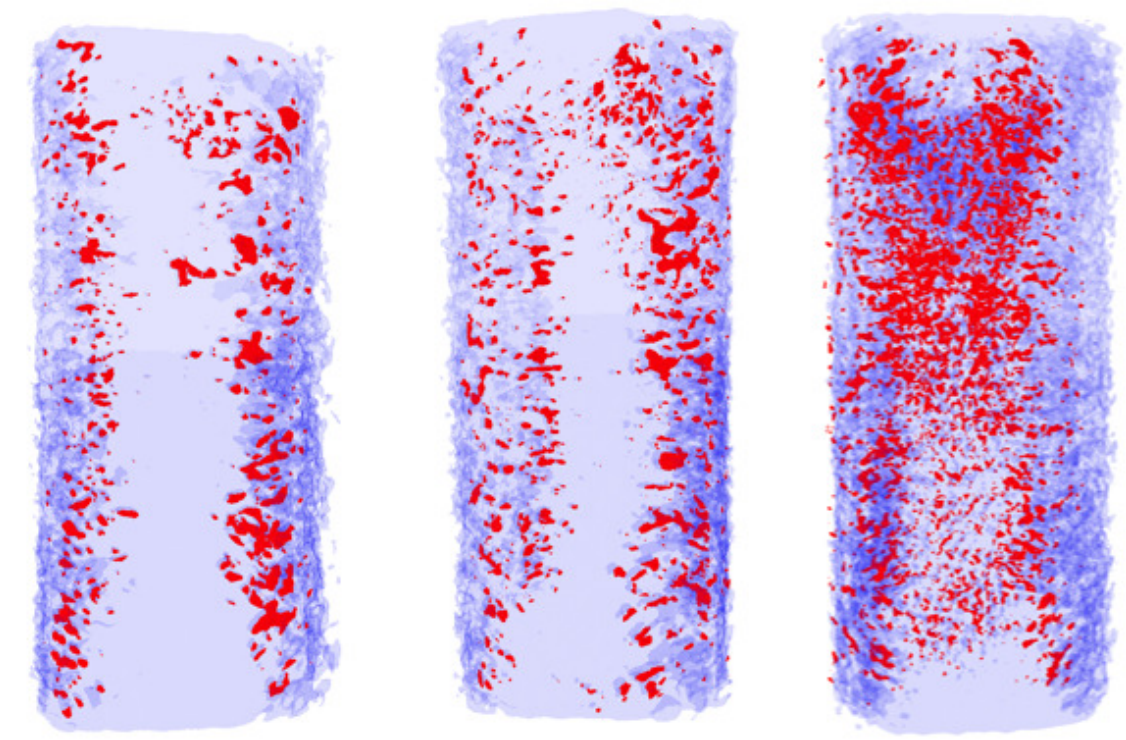

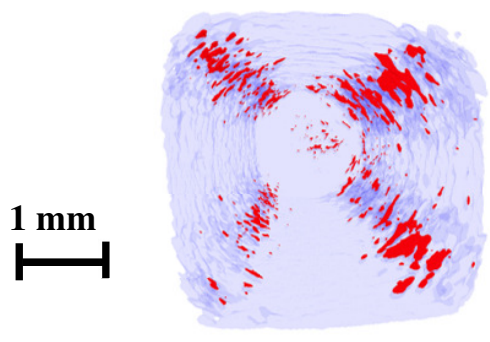

(a)

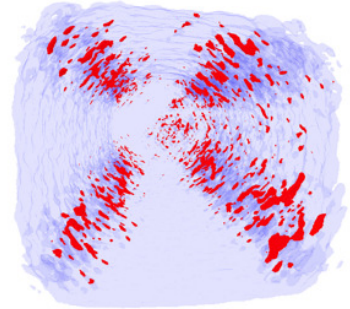

(b)

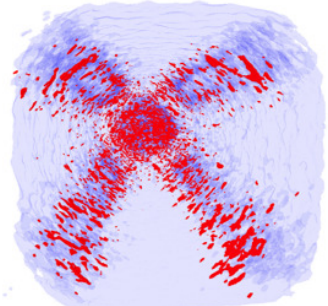

(c)

Fig 8. XCT 3D visualisation of porosity content and distribution for (top) Z view and (bottom) X view at (a) $0.15 \mathrm{~mm}$ hatch distance $400 \mathrm{~mm} / \mathrm{s}$ scan speed (b) $0.15 \mathrm{~mm}$ hatch distance $800 \mathrm{~mm} / \mathrm{s}$ scan speed. and (c) $0.20 \mathrm{~mm}$ hatch distance and $400 \mathrm{~mm} / \mathrm{s}$ scan speed.

Although $800 \mathrm{~mm} / \mathrm{s} 0.15 \mathrm{~mm}$ hatch distance (Fig 8b) has higher porosity values, the bulk area for both $400 \mathrm{~mm} / \mathrm{s}$ (Fig $8 \mathrm{a}$ ) and $800 \mathrm{~mm} / \mathrm{s}$ (Fig 8b) contain significantly less porosity content than the larger hatch distance of $0.20 \mathrm{~mm}$ (Fig 8c) which is likely due to lack of fusion porosity forming between laser scan paths due to the larger hatch distance. Lack of fusion porosity content within the contour regions is likely due to unoptimised SLM contour parameters which were not considered in the scope of this study. 


\subsection{Surface Roughness}

The surface quality of AM structures influences resultant component mechanical and thermal properties [41,42] and while rough surface finish is usually not desired due to its relation with reduced strength [42-44], rough surfaces can also be beneficial for certain applications such as thermal transfer through enhanced fluid flow and mixing [41,45]. Previous studies investigating common AM materials including stainless steel, titanium, aluminium and cobalt chrome have reported both positive and negative effects of varying SLM laser power, hatch distance and scan speed parameters on surface quality and strength of fabricated components [42-44,46,47]. However, surface quality analysis of more novel SLM materials have seen less investigation with SLM pure silver surface roughness yet to be reported. Accordingly, the surface roughness of an as built SLM pure silver structure is reported with the aim of aiding future SLM process parameter optimisation. SLM contour parameters remained constant at $400 \mathrm{~mm} / \mathrm{s} 0.15 \mathrm{~mm}$ for this study and therefore this sample was selected as a representative sample of surface roughness.

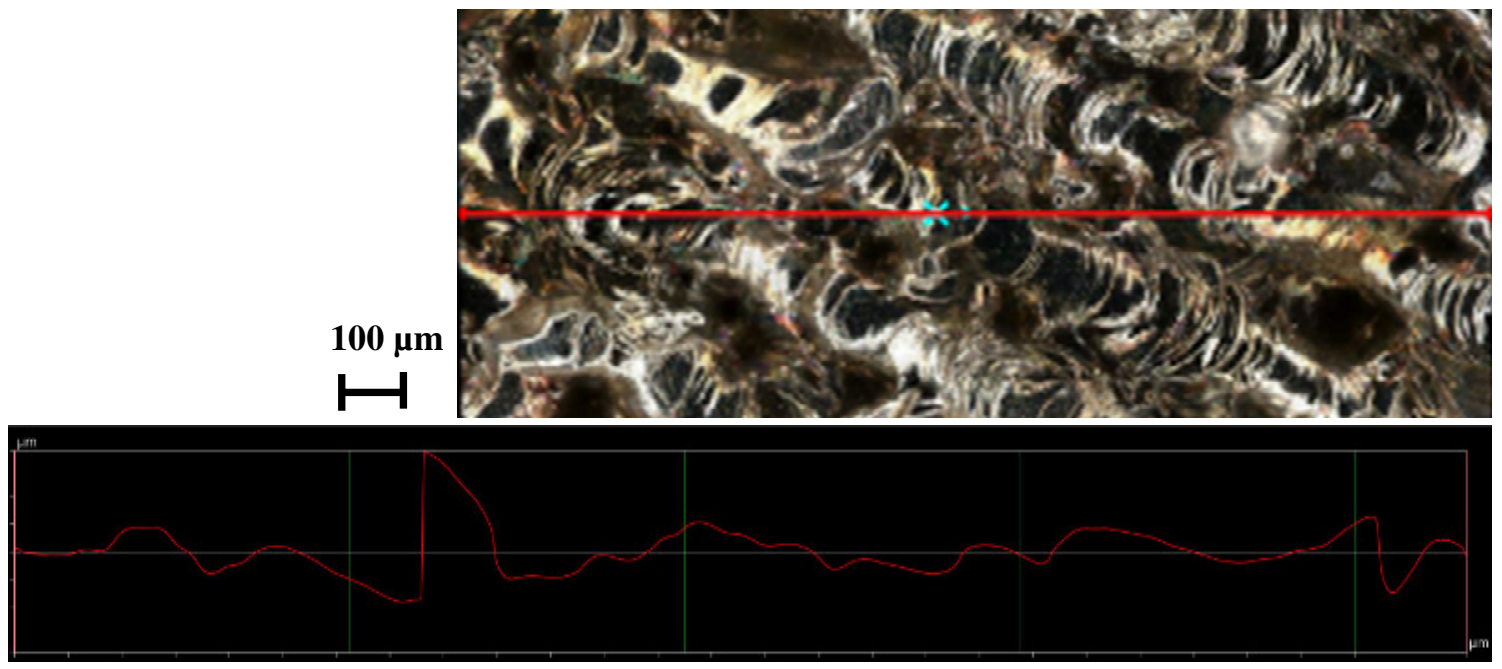

Fig 9. Digital microscope images of horizontal AM pure silver as built surface roughness and surface profile.

Digital microscopy techniques were utilised to generate surface roughness profiles for horizontal (Fig 9) and vertical (Fig 10) surfaces and average peak and trough deviation (Ra) recorded. Ra values of $5.89 \mu \mathrm{m}$ for horizontal surfaces and $16.03 \mu \mathrm{m}$ for the vertical edge were recorded. While further parameter optimisation and development should result in improved surface quality for SLM pure silver the Ra values recorded are comparable with Ra values reported for current materials such as titanium $\mathrm{Ra}=\sim 10.3 \mu \mathrm{m}$ [48] Cobalt chrome $\mathrm{Ra}=\sim 8-12 \mu \mathrm{m}$ [46] and aluminium $\mathrm{Ra}=\sim 4.32-7.50 \mu \mathrm{m}[47]$ respectively. 


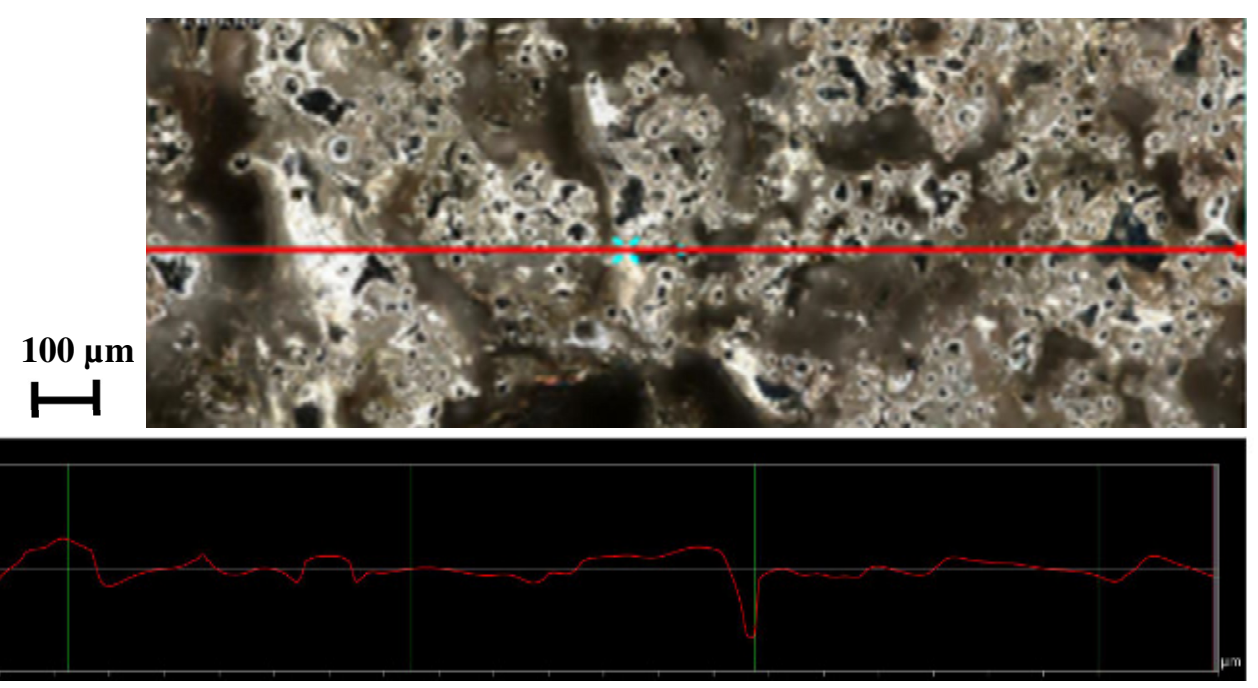

Fig 10. Digital microscope images of vertical AM pure silver as built surface roughness and surface profile.

\subsection{Fractography}

Following tensile testing the fracture surfaces of each sample were investigated using optical and SEM microscopy. Fig 11 shows comparative optical microscopy images of fracture surfaces produced for $400 \mathrm{~mm} / \mathrm{s}$ and $0.15 \mathrm{~mm}$ and $0.16 \mathrm{~mm}$ scan speeds and hatch distances. Unmolten powder particles are clearly visible at both fracture surfaces where lack of fusion porosity defects have been created during the AM process. This could be due to poor laser absorption of the pure silver material and/or the requirement for further SLM process parameter development.

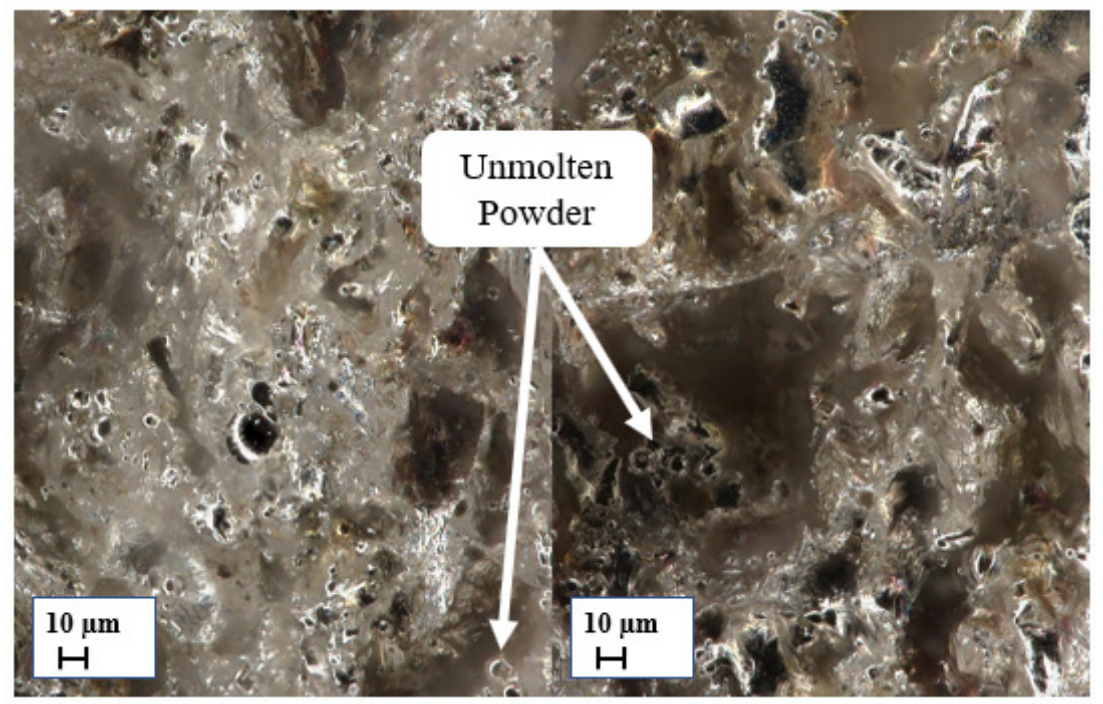

(a)

(b)

Fig 11. Optical microscopy image of AM pure silver fracture surfaces for $400 \mathrm{~mm} / \mathrm{s}$ scan speed at (a) $0.16 \mathrm{~mm}$ hatch distance and (b) $0.15 \mathrm{~mm}$ hatch distance. 
Further SEM analysis (Fig 12) was also conducted on $800 \mathrm{~mm} / \mathrm{s}$ scan speed and $0.16 \mathrm{~mm}$ hatch distance fracture surface as this sample had the highest Youngs Modulus of all samples which also confirmed the lack of fusion porosity voids and unmolten powder. Overall, the fractography shows that the failure is significantly influenced by the defects and the mechanical performance can be optimised by reducing the porosity defects by optimising the SLM process parameters.

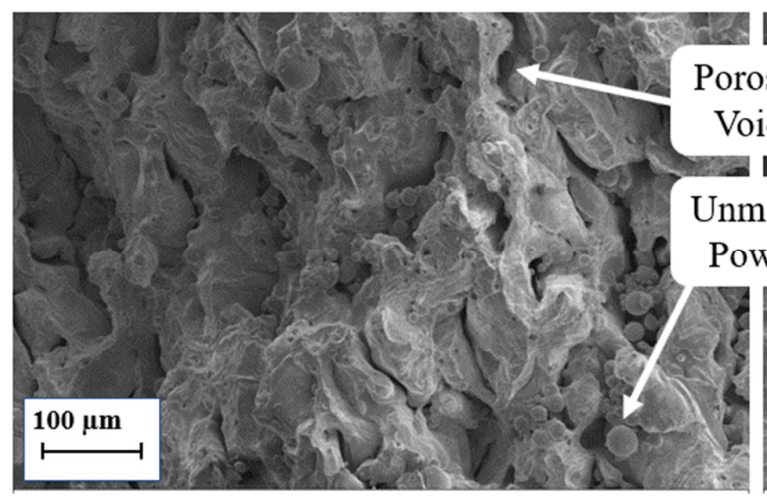

(a)

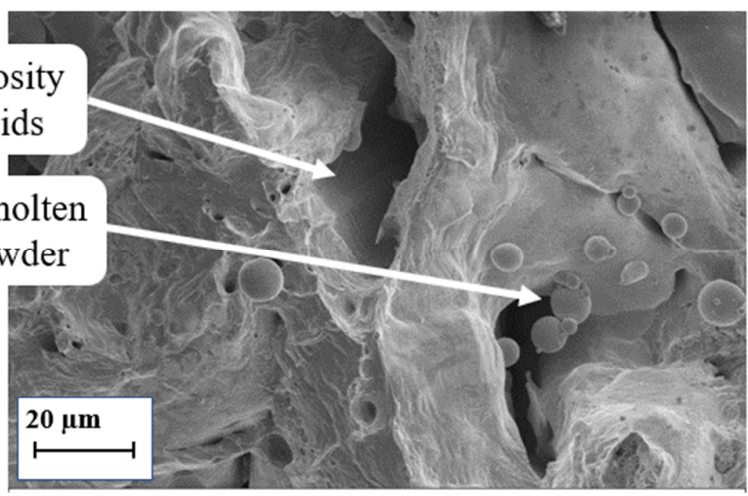

(b)

Fig 12. SEM images of AM pure silver fracture surface for $800 \mathrm{~mm} / \mathrm{s}$ scan speed and $0.16 \mathrm{~mm}$ hatch distance showing (a) lack of fusion porosity defects and (b) unmolten powder particles.

Evaluating the stress-strain curve shown in Fig. 3 in conjunction with fractography (Fig. 12) it was clear that the strain associated with failure was representative of a ductile material. However, a moderate ductile classification was most appropriate as the performance and associated failure of all $\mathrm{Ag}$ samples exceeded a 5\% strain but falls close to or below $10 \%$ at failure. The reason for moderate ductile behaviour can be identified from the SEM fractography (Fig. 12) which reveals the SLM porosity aiding failure. As a result of this the samples were unable to exhibit pure ductile performance attributed to traditionally manufactured silver that is homogeneous in nature. However, an appreciable amount of permanent plastic deformation accompanies the fracture that was largely manifested macroscopically across the cross-section in the form of distortion.

\section{Conclusions}

In this study pure silver tensile samples were fabricated using SLM AM. Scan speed and hatch distance SLM parameters were varied to ascertain the relationship between AM pure silver density and pore defect properties and yield strength, Youngs Modulus, yield strain and ultimate tensile strength. XCT analysis and 3D visualisation techniques were utilised to verify the corresponding porosity morphology and distribution throughout the samples. SEM and optical microscopy techniques were then used to analyse the pure silver fracture surfaces and digital microscopy utilised to analyse SLM pure silver surface roughness. SLM scan speed and hatch distance parameters were shown to have a significant effect on pore defect creation, morphology 
and distribution within SLM pure silver structures. Porosity morphology, content and distribution varied significantly as energy density at the powder bed was altered through SLM parameter adjustment, which in turn effected pure silver density and mechanical performance. Generally, as hatch distances increased the number of pore defect and therefore surface area of those pore defects within the sample bulk areas increased. This was due to lack of fusion porosities being created between laser scan paths due to the larger distances between laser scans. Yield strength and ultimate tensile strength for all scan speed samples was seen to reduce as hatch distance increased. Porosity morphology and average pore size was seen to have the most significant effect on Youngs Modulus values. When average pore size was calculated the samples with the largest average pore size $>0.0132 \mathrm{~mm}^{2}$ had the lowest Youngs Modulus values. Smaller finer distributed pore defects (weather lack of fusion, keyhole or blowhole) resulted in a higher Youngs Modulus. A higher bulk density resulted in higher yield and ultimate strength with Youngs Modulus being affected by pore defect morphology. Bulk density values as high as $99.8 \%$ are reported for pure silver and SLM. Overall, it is clear that contour process parameters require further optimisation to reduce lack of fusion pore defects within these regions. However, surface roughness was shown to be comparable with current SLM materials. Samples were shown to fail at lack of fusion porosity regions with unmolten powder clearly visible in SEM and optical microscopy analysis of the fracture surfaces. The mechanical properties of AM pure silver can be altered through SLM process parameter adjustments resulting in different densities within the bulk and contour regions. Pore defect morphology and distribution within these regions was shown to effect yield strength and Youngs Modulus of the samples differently. These results offer the potential for future work regarding custom yield strength and Youngs Modulus creation through lattice structure design of bulk and contour regions. These are preliminary results that offer a benchmark for SLM pure silver.

\section{Acknowledgements}

This research was supported by the University of Wolverhampton and 6Dme Ltd.

\section{Data availability}

The data that supports the findings of this study are available from the corresponding author upon reasonable request.

\section{References}

[1] D. Jafari, W.W. Wits, The utilization of selective laser melting technology on heat transfer devices for thermal energy conversion applications: A review, Renew. Sustain. Energy Rev. 91 (2018) 420-442. doi:10.1016/j.rser.2018.03.109.

[2] Ernst \& Young, EY's Global 3D printing Report 2016, Ernst and Young. (2016) 1-26. doi:10.1002/art.27698.

[3] J. Maier, Additive manufacturing UK 2018-25, (2018). http://am-uk.org/wpcontent/uploads/2017/11/AM-UK_Strategy_Publication_Amends_Novermber_Digital.pdf. 
[4] M. Colopi, L. Caprio, A.G. Demir, B. Previtali, Selective laser melting of pure Cu with a 1 kW single mode fiber laser, Procedia CIRP. 74 (2018) 59-63. doi:10.1016/j.procir.2018.08.030.

[5] A. Aversa, M. Moshiri, E. Librera, M. Hadi, G. Marchese, D. Manfredi, M. Lorusso, F. Calignano, S. Biamino, M. Lombardi, M. Pavese, Single scan track analyses on aluminium based powders, J. Mater. Process. Technol. 255 (2018) 17-25. doi:10.1016/j.jmatprotec.2017.11.055.

[6] L.E. Criales, Y.M. Arısoy, B. Lane, S. Moylan, A. Donmez, T. Özel, Laser powder bed fusion of nickel alloy 625: Experimental investigations of effects of process parameters on melt pool size and shape with spatter analysis, Int. J. Mach. Tools Manuf. 121 (2017) 22-36. doi:10.1016/j.ijmachtools.2017.03.004.

[7] S.M. Thompson, Z.S. Aspin, N. Shamsaei, A. Elwany, L. Bian, Additive manufacturing of heat exchangers: A case study on a multi-layered Ti-6Al-4V oscillating heat pipe, Addit. Manuf. 8 (2015) 163-174. doi:10.1016/j.addma.2015.09.003.

[8] M.K. Thompson, G. Moroni, T. Vaneker, G. Fadel, R.I. Campbell, I. Gibson, A. Bernard, J. Schulz, P. Graf, B. Ahuja, F. Martina, Design for Additive Manufacturing: Trends, opportunities, considerations, and constraints, CIRP Ann. - Manuf. Technol. 65 (2016) 737-760. doi:10.1016/j.cirp.2016.05.004.

[9] S. Bose, D. Ke, H. Sahasrabudhe, A. Bandyopadhyay, Additive manufacturing of biomaterials, Prog. Mater. Sci. 93 (2018) 45-111. doi:10.1016/j.pmatsci.2017.08.003.

[10] E. Cyr, A. Lloyd, M. Mohammadi, Tension-compression asymmetry of additively manufactured Maraging steel, J. Manuf. Process. 35 (2018) 289-294. doi:10.1016/j.jmapro.2018.08.015.

[11] M. Sadowski, L. Ladani, W. Brindley, J. Romano, Optimizing quality of additively manufactured Inconel 718 using powder bed laser melting process, Addit. Manuf. 11 (2016) 60-70. doi:10.1016/j.addma.2016.03.006.

[12] S.N. Joshi, E.M. Dede, Two-phase jet impingement cooling for high heat flux wide band-gap devices using multi-scale porous surfaces, Appl. Therm. Eng. 110 (2017) 10-17. doi:10.1016/j.applthermaleng.2016.08.146.

[13] I. Yadroitsev, A. Gusarov, I. Yadroitsava, I. Smurov, Single track formation in selective laser melting of metal powders, J. Mater. Process. Technol. 210 (2010) 1624-1631. doi:10.1016/j.jmatprotec.2010.05.010.

[14] P. O’Regan, P. Prickett, R. Setchi, G. Hankins, N. Jones, Metal Based Additive Layer Manufacturing: Variations, Correlations and Process Control, Procedia Comput. Sci. 96 (2016) 216-224. doi:10.1016/j.procs.2016.08.134.

[15] A. Yan, Z. Wang, T. Yang, Y. Wang, Z. Ma, Microstructure, thermal physical property and surface morphology of W-Cu composite fabricated via selective laser melting, Mater. Des. 109 (2016) 79-87. doi:10.1016/j.matdes.2016.07.049.

[16] R. Guschlbauer, S. Momeni, F. Osmanlic, C. Körner, Process development of 99.95\% pure copper processed via selective electron beam melting and its mechanical and physical properties, Mater. Charact. 143 (2018) 163-170. doi:10.1016/j.matchar.2018.04.009.

[17] J. Zhang, B. Song, Q. Wei, D. Bourell, Y. Shi, A review of selective laser melting of aluminum alloys: Processing, microstructure, property and developing trends, J. Mater. Sci. Technol. 35 (2019) 270-284. doi:10.1016/j.jmst.2018.09.004.

[18] F.H. Kim, S.P. Moylan, E.J. Garboczi, J.A. Slotwinski, Investigation of pore structure in cobalt chrome additively manufactured parts using X-ray computed tomography and three-dimensional image analysis, Addit. Manuf. 17 (2017) 23-38. doi:10.1016/j.addma.2017.06.011.

[19] M. Bayat, A. Thanki, S. Mohanty, A. Witvrouw, S. Yang, J. Thorborg, N.S. Tiedje, J.H. Hattel, Keyholeinduced porosities in Laser-based Powder Bed Fusion (L-PBF) of Ti6Al4V: High-fidelity modelling and experimental validation, Addit. Manuf. 30 (2019) 100835. doi:10.1016/j.addma.2019.100835. 
[20] C. Pleass, S. Jothi, Influence of powder characteristics and additive manufacturing process parameters on the microstructure and mechanical behaviour of Inconel 625 fabricated by Selective Laser Melting, Addit. Manuf. 24 (2018) 419-431. doi:10.1016/j.addma.2018.09.023.

[21] J.H. Tan, W.L.E. Wong, K.W. Dalgarno, An overview of powder granulometry on feedstock and part performance in the selective laser melting process, Addit. Manuf. 18 (2017) 228-255. doi:10.1016/j.addma.2017.10.011.

[22] N. Li, S. Huang, G. Zhang, R. Qin, W. Liu, H. Xiong, G. Shi, J. Blackburn, Progress in additive manufacturing on new materials: A review, J. Mater. Sci. Technol. 35 (2019) 242-269. doi:10.1016/j.jmst.2018.09.002.

[23] M. Fateri, A. Gebhardt, J.-S. Hötter, M. Knothe, F.M. Schmidt, H. Rieper, Numerical and Experimental Investigation of Selective Laser Melting of Silver, Fraunhofer Direct Digit. Manuf. Conf. (DDMC), Berlin. (2012).

[24] S. Zhang, S. Rauniyar, S. Shrestha, A. Ward, K. Chou, An experimental study of tensile property variability in selective laser melting, J. Manuf. Process. 43 (2019) 26-35. doi:10.1016/j.jmapro.2019.03.045.

[25] J. Clayton, R. Deffley, Optimising metal powders for additive manufacturing, Met. Powder Rep. 69 (2014) 14-17. doi:10.1016/S0026-0657(14)70223-1.

[26] D. Bradley, Every silver-lined solar cell, Mater. Today. 12 (2009) 10. doi:10.1016/s1369-7021(09)70291-3.

[27] D. Bradley, Silver nanowires, at a stretch, Mater. Today. 15 (2012) 361. doi:10.1016/s1369-7021(12)70153-0.

[28] S. Maharubin, Y. Hu, D. Sooriyaarachchi, W. Cong, G.Z. Tan, Laser engineered net shaping of antimicrobial and biocompatible titanium-silver alloys, Mater. Sci. Eng. C. 105 (2019) 110059. doi:10.1016/j.msec.2019.110059.

[29] G. Abbas Gohar, T. Manzoor, A.N. Shah, Investigation of thermal and mechanical properties of $\mathrm{Cu}-\mathrm{Al}$ alloys with silver addition prepared by powder metallurgy, J. Alloys Compd. 735 (2018) 802-812. doi:10.1016/j.jallcom.2017.11.176.

[30] J. Robinson, M. Stanford, A. Arjunan, Stable formation of powder bed laser fused 99.9\% silver, Mater. Today Commun. 24 (2020) 101195. doi:10.1016/j.mtcomm.2020.101195.

[31] A. Sun, Z. Wu, X. Dong, B. Duan, D. Wang, Effects of Ag addition on electrical and thermal properties of Mo-Cu composites, J. Alloys Compd. 657 (2016) 8-11. doi:10.1016/j.jallcom.2015.10.098.

[32] J. Fieres, P. Schumann, C. Reinhart, Predicting failure in additively manufactured parts using X-ray computed tomography and simulation, Procedia Eng. 213 (2018) 69-78. doi:10.1016/j.proeng.2018.02.008.

[33] S. Coeck, M. Bisht, J. Plas, F. Verbist, Prediction of lack of fusion porosity in selective laser melting based on melt pool monitoring data, Addit. Manuf. 25 (2019) 347-356. doi:10.1016/j.addma.2018.11.015.

[34] W. Xiong, L. Hao, Y. Li, D. Tang, Q. Cui, Z. Feng, C. Yan, Effect of selective laser melting parameters on morphology, microstructure, densification and mechanical properties of supersaturated silver alloy, Mater. Des. 170 (2019) 107697. doi:10.1016/j.matdes.2019.107697.

[35] N. Ortega, S. Martínez, I. Cerrillo, A. Lamikiz, E. Ukar, Computed tomography approach to quality control of the Inconel 718 components obtained by additive manufacturing (SLM), Procedia Manuf. 13 (2017) 116123. doi:10.1016/j.promfg.2017.09.018.

[36] H. Lee, J.H.J. Kim, J.H. Moon, W.W. Kim, E.A. Seo, Correlation between pore characteristics and tensile bond strength of additive manufactured mortar using X-ray computed tomography, Constr. Build. Mater. 226 (2019) 712-720. doi:10.1016/j.conbuildmat.2019.07.161. 
[37] E. Abele, H.A. Stoffregen, M. Kniepkamp, S. Lang, M. Hampe, Selective laser melting for manufacturing of thin-walled porous elements, J. Mater. Process. Technol. 215 (2015) 114-122.

doi:10.1016/j.jmatprotec.2014.07.017.

[38] A. Zhukov, B. Barakhtin, P. Kuznetsov, Study of Strength Characteristics of Steel Specimens after Selective Laser Melting of Powder Materials 17-4PH, 316L, 321, Phys. Procedia. 89 (2017) 179-186. doi:10.1016/j.phpro.2017.08.012.

[39] P. Hanzl, M. Zetek, T. Bakša, T. Kroupa, The influence of processing parameters on the mechanical properties of SLM parts, Procedia Eng. 100 (2015) 1405-1413. doi:10.1016/j.proeng.2015.01.510.

[40] B. Zhang, S. Liu, Y.C. Shin, In-Process monitoring of porosity during laser additive manufacturing process, Addit. Manuf. 28 (2019) 497-505. doi:10.1016/j.addma.2019.05.030.

[41] L. Ventola, F. Robotti, M. Dialameh, F. Calignano, D. Manfredi, E. Chiavazzo, P. Asinari, Rough surfaces with enhanced heat transfer for electronics cooling by direct metal laser sintering, Int. J. Heat Mass Transf. 75 (2014) 58-74. doi:10.1016/j.ijheatmasstransfer.2014.03.037.

[42] G. Dursun, S. Ibekwe, G. Li, P. Mensah, G. Joshi, D. Jerro, Influence of laser processing parameters on the surface characteristics of 316L stainless steel manufactured by selective laser melting, Mater. Today Proc. 26 (2020) 387-393. doi:10.1016/j.matpr.2019.12.061.

[43] J. Gockel, L. Sheridan, B. Koerper, B. Whip, The influence of additive manufacturing processing parameters on surface roughness and fatigue life, Int. J. Fatigue. 124 (2019) 380-388.

doi:10.1016/j.ijfatigue.2019.03.025.

[44] M. Nakatani, H. Masuo, Y. Tanaka, Y. Murakami, Effect of Surface Roughness on Fatigue Strength of Ti6Al-4V Alloy Manufactured by Additive Manufacturing, Procedia Struct. Integr. 19 (2019) 294-301. doi:10.1016/j.prostr.2019.12.032.

[45] T. Alam, M.H. Kim, A comprehensive review on single phase heat transfer enhancement techniques in heat exchanger applications, Renew. Sustain. Energy Rev. 81 (2018) 813-839. doi:10.1016/j.rser.2017.08.060.

[46] L. Tonelli, A. Fortunato, L. Ceschini, CoCr alloy processed by Selective Laser Melting (SLM): effect of Laser Energy Density on microstructure, surface morphology, and hardness, J. Manuf. Process. 52 (2020) 106-119. doi:10.1016/j.jmapro.2020.01.052.

[47] A. Majeed, A. Ahmed, A. Salam, M.Z. Sheikh, Surface quality improvement by parameters analysis, optimization and heat treatment of AlSi10Mg parts manufactured by SLM additive manufacturing, Int. J. Light. Mater. Manuf. 2 (2019) 288-295. doi:10.1016/j.ijlmm.2019.08.001.

[48] Y. Eyzat, M. Chemkhi, Q. Portella, J. Gardan, J. Remond, D. Retraint, Characterization and mechanical properties of As-Built SLM Ti-6Al-4V subjected to surface mechanical post-treatment, Procedia CIRP. 81 (2019) 1225-1229. doi:10.1016/j.procir.2019.03.298. 